\title{
A Mini Review on Anti-Cancerous Potentials of Snake Venoms
}

\author{
Sana Ullah ${ }^{1}$, Tauseef Ahmad ${ }^{2, *}$ \\ ${ }^{1}$ Department of Animal Sciences, Quaid-i-Azam University Islamabad, Islamic Republic of Pakistan \\ ${ }^{2}$ Department of Microbiology, Hazara University Mansehra, Islamic Republic of Pakistan
}

Copyright (C) 2015 Horizon Research Publishing All rights reserved.

\begin{abstract}
Snake has been known as a group of dangerous animals to everyone around the world since time unmemorable. Its venom is considered as a source of morbidity and mortality in human beings but it is also an important therapeutic agent for treating various types of cancers such leukaemia, breast cancer, ovarian cancer and prostate cancer etc. There is a wide range of snake species around the globe having different types of venoms. These different types of venom are having different types of activities such as cytotoxicity, apoptosis inducing, antiproliferative activity, platelets activation through CLEC-2 (C-type lectin-like receptor 2) platelet targeting and inhibition of RNA and DNA production.
\end{abstract}

Keywords Snake, Cancer, Leukaemia, Venoms

\section{Introduction}

Cancer is one of the most life treating multi-faceted diseases that occur on account of uncontrolled cell production, accompanied by attack of local tissues and their metastasize ability. Cancer is ranking third for leading death source after infectious and cardiac diseases [1,2]. According to a report of 2008, cancer counted for 7.6 million mortalities all around the globe, frequently in developing countries, and is predicted to be on increase due to behaviours leading to cancer, populations' expansion and aging [3]. External factors such as viruses, tobacco, chemicals and radiations as well as internal factors such as mutations, hormones and immune conditions may be involved in causing cancer. These factors may act in sequence or together to initiate or stimulate cancer.

\section{Treatment Modalities for Cancer}

In current scenario cancer is quite key problem of public health as it is contributing to high mortality rate across the globe. To cope with this there is an urgent need of finding better treatment option. Currently treatments available are immunotherapy, chemotherapy, hormonal therapy, radiation therapy and surgery [4]. Chemotherapy is gold standard option [5] but unfortunately it often leads to some grave ill effects [6]. Keeping in view this situation there has been development of new strategies for achieving novel drugs that can have anticancer activity. These drugs are most likely being obtained from naturally available resources that may elevate the efficacy of chemotherapy [7]. Biotoxins carry a huge quantity of natural novel compounds that can have toxicological effects as well as pharmacological effects, by simply killing or hurting other organism, and can serve as initiating material for designing drugs in order to fight pathophysiological problems including cancer [8]. Many venomous toxins have shown great anti-tumorous activities including snake venom which can be used as a new and innovative therapeutic agent. It is having prime role in cancer treatment [9].

\section{Composition and Classification of Snake venoms}

Venom glands produce venom in snake, which is collected by employing great scientific approaches and techniques [10]. Venoms are of different types depending upon the habitat, age and location etc. of snakes [11]. In case of injecting, it is having toxic effect but if ingested, it is harmless. This is usually a viscous liquid and can be dried in crystals form [12]. Venoms of snakes are a mixture of minor organic substances such as acetylcholine, nucleosides and citrates as well as proteinaceous peptidyl toxins and enzymes $[13,14,15]$. It is also containing free amino acids, carbohydrates, lipids and inorganic cations such as sodium, magnesium, potassium and calcium etc. [16]. It is also having a number of bioactive substances as well as different natural compounds such as cytotoxic, cardiotoxic, neurotoxic and other surplus compounds, active in nature [17].

On account of variation in effects and action, venoms of snakes are classified in main 3 categories cytotoxin, hemotoxin and neurotoxin [18]. Neurtoxins target CNS, ultimately lead to breathing problems and heart failure. They inhibit movement ions across cell membrane and blocks communication between neurons [19]. Hemotoxins destroy RBCs and affect blood function, cardiovascular system and 
target hosts' muscle tissue. Cytotoxins target specific muscles and cellular sites. Neurotoxic venoms are contained by sea snakes, kraits and cobras whereas hemotoxic venoms are found in copper heads and rattle snakes. Snake bites result in injecting venoms into prey subcutaneously, that result in systemic (such as hypotensive, anticoagulant activities and myotoxicity), and local effects (such as demonecrosis and haemorrhage) [20,21].

\section{Mechanism of Action}

Snake venoms cause fibrinolytic activities in patient. It consists of enzymes that quickly clots fibrinogen and imposes strong lethal effect. These enzymes abolish firbrinogen from circulation with no conversion to fibrin which lead to heavy aggregation of platelets. This strong activity, fibrinolytic activity, is due to the presence of different enzymes such as lebetase (Viper alebetina), atroxase (Crotalus atroz), fibrolase (Agkistrodon controtrix), natrahagin proteinase (Naja naja), and fibrogenases (Viper alebatina). Such type of activity has also been shown by Hannahpep and Batraxin [22,23]. The peptide bonds of fibrinogen are cleaved by different proteinases present in venom such as fibrinolytic proteinases, plasminogen activator and thrombin. Deep vein and peripheral atrial thrombosis are caused by snake venoms. These also cause sickle cell crisis, priapism, myocardial and cerebral infarction. Toxins of venoms show antitumor activity on account of $\mathrm{H} 2 \mathrm{O} 2$ release in oxygen dependant enzymatic reaction and inflammatory response is mediated by TNF- $\alpha$, IL2, IL8 and other soluble factors [24].

\section{Anti-Cancerous Potential of Snake Venoms}

It was recognized that snake venom contains therapeutic potentials and hence it was used for treating cancer in lab animal first [25]. Venoms isolated from Walterinnesia aegyptia singly or when combine with nanoparticles of silica are used for treating prostate cancerous cells while toxins extracted from Viperalebentina turnica are used for treating ovarian cancerous cells [26]. Salmosin from Korean snakes interact with integrin and induce apoptosis through competing with extracellular matrix for direct binding on cell surface to integrin [27]. Aggretin is a protein derived from snake venom, activate platelets by targeting platelet CLEC-2 (C-type lectin-like receptor 2 - identified as a receptor for the platelet activating snake venom rhodocytin [41]) so it pose an anti-tumorous metastatic effect [28]. Venoms $C$. albolabris and $C$. rhodostoma are having same cytotoxic effect on Hep-G2 (human liver carcinoma cell line), Cha Go (Human bronchogenic carcinoma), SW 620 (colon adenocarcinoma, Dukes' type $\mathrm{C}$-human intestine epithelial cells), BT474 (ductal carcinoma - human mammary gland) and KATO-III (gastric carcinoma - human stomach) cancerous cell lines. Both showed great potential on BT474 and KATO-III cells as compared to anticancer drugs [29].

DNA and RNA production was markedly decreased in breast cancer by apply cobra snake venoms in crude form [30]. Venoms of Egyptian cobra showed potential activities against breast cancer and prostate cancerous cell lines [31,32]. Cytotoxic activity in melanoma was observed for PLA2 (Phospholipase A2 - Enzymes releasing fatty acids from $2^{\text {nd }}$ carbon group of glycerol) extracted of Bothropsnewweildii [33] and for Crotalusduris susterrificus and Bothropsjaroraca cytotoxicity in leukemic and sarcoma tissue was observed [34]. Venome from crotalidae, viperaidae and elapidae killed sarcoma and melanoma cells and showed cytotoxic and inhibitory activities in chodrosarcoma cell lines [35]. Saxatilin and Disintigrin extracted of Korean snakes inhibited ovarian cancerous cells proliferation [32]. Study showed that crude venome of cobra reduced nucleic acid production in breats cancerous tissues in vitro which suggest it as a potent therapy for breast cancer in future [36].

Venoms from Naja najaatra showed inhibition of K562 (chronic myelogenous leukemia (CML) - human bone marrow) cells growth and exhibited apoptosis in cancerous cells. Walterinnesi aaegyptia (WEV) venom alone as well as in combination with nanoparticles of silica (WEV+NP) arrested growth and apoptosis of prostate and breast cancer cells [37]. The same combination (WEV+NP) strengthened the antitumorous activity in 2 cell lines of breast cancer [38]. Contortrostatin extracted of southern copperhead snake limited growth of tumour and angiogenesis as well as limits tumour metastasis severly [39,40]. Snake venoms cystatis inhibited the metastasis and invasion of tumorous cells and suppress growth, metastasis and melanoma invasion in mouse. Disintegrin is a potential inhibitor of cell adhesion as well as platelets aggregation [40].

\section{Conclusions}

Although snake venom is a disastrous compound and is considered as one of the destroying chemical around the globe yet is therapeutically very efficient against different cancer types. Different types are snakes are bearing different type of venom, which make its composition, activities and mechanism of action quite different. Till now different studies that are already conducted are showing efficacy of venom against cancer. Still many of these venom types are remaining to be studied. Therefore researchers and scientists are motivated to study the anti-cancerous activity as well as activities of these venoms against other disorders, specifically studying it at local vicinities.

\section{REFERENCES}

[1] F. M. Kievit, M. Zhang M. Cancer NanotheranosticsImproving Imaging and Therapy by Targeted Delivery across Biological Barriers. Adv Mater, Vol. 23: 217-247. 2011.

[2] American Cancer Society. Global cancer facts and figures, 2nd edn. American Cancer Society, Atlanta. 2011. 
[3] J. Ahmedin, F. Bray, M. Center M. Global cancer statistics. CA: Cancer J Clinicians, Vol. 61:69-90. 2011.

[4] R. Baskar, K. A. Lee, R. Yeo. Cancer and radiation therapy: current advances and future directions. Int J Med Sci, Vol. 9: 193-9. 2012.

[5] R. C. Soletti, G. P. de Faria, J. Vernal. Potentiation of anticancer-drug cytotoxicity by sea anemone pore-forming proteins in human glioblastoma cells. Anticancer Drugs, Vol. 19: 517-25. 2008.

[6] M. S. Libério, G. A. Joanitti, W. Fontes. Anticancer peptides and proteins: a panoramic view. Protein Pept Lett, Vol. 20: 380-91. 2013.

[7] D. Lai, S. Visser-Grieve, X. Yang. Tumour suppressor genes in chemotherapeutic drug response. Biosci Rep, Vol. 32: 361-74. 2012.

[8] T. E. Heinen, A. B. da Veiga. Arthropod venoms and cancer. Toxicon, Vol. 57: 497-511. 2011.

[9] C. Aarti, A. Khusro. Snake venom as Anticancer agentCurrent Perspective .Int. J. Pure App. Biosci, Vol. 1:24-29. 2013.

[10] J. C. Daltr, W. Wuster, R. S. Thorpe. Diet and snake venom evolution. Nature, Vol. 379:537-540. 1996.

[11] A. K. Tashima, L. Sanz, A. C. M. Camargo, J. J. Calvete. Snake venomics of the Brazilian pitvipers, Bothrops cotiara and Bothrops fonsecai, Identification of taxonomy markers. J. Proteo, Vol. 71:473-485. 2008.

[12] S. D. Arid. Ophidian envenomation strategies and the role of purines. Toxicon, Vol. 40: 335-393. 2002

[13] G. Leon, L. Sanchez, A. Hernandez, M. Villalta, M. Herrera, A. Segura. Immune response towards snake venoms. Inflamm Allergy Drug Targets, Vol. 10: 381-398. 2011.

[14] R. Doley, R. M. Kini. Protein complexes in snake venom. Cellular and Molecular Life sciences, Vol. 66:2851-1. 2009.

[15] M. M. D. V. Santos, C. D. Santana, J. R. Giglio, R. J. Da Silva, S. V. Sampaio, A. M. Soares. Antitumor effect of an L-amino acid oxidase isolated from Bothrops jararaca snake venom. Basic Clin Pharmacol Toxicol, Vol. 102:533-542. 2008.

[16] Ferrer. Snake venom: The pain and potential of the venom. The cold blooded news.Pp.28. 2001.

[17] M. W. Bradbury, R. Deane. Permeability of the blood-brain barrier to lead. Neurotoxicology, Vol. 14: 131-6. 1993.

[18] A. T. Tu. Overview of snake venom chemistry. Adv Exp. Med. Biol, Vol. 39:37-62. 1996.

[19] C. D. Cher, A. Armuga, Y. Z. Zhu, K. Jeyaseelan. Molecular basis of cardiotoxicity upon cobra envenomation. Cell Mol Life Sci, Vol. 62:105-118. 2005.

[20] D. S. Wang, M. Hanamoto, F. Fang, M. Ohba, M. Ishii, F. Kinura, E. Higaki, H. Senga. Defibrogenating effects of batroxobin (defibrase in rat and inhibition of human vascular muscle cells and by the plasma of batroxobin treated rats in vitro. Atherosclerosis, Vol. 156:73-80. 2001.

[21] A. Gomes, P. Hannahpep De. A novel fibrinolytic peptide from the Indian King Cobra Ophiophagus Hannah venom,
Biochemic. Biophys. Res. Comm, Vol. 266: 488-491. 1999.

[22] R. J. Da Silva, D. Fecchio, B. Barraviera. Antitumor effect of snake venoms", J. Venom Anim. Toxins, Vol. 2: 79-90. 1996.

[23] A. Calmett, A. Saenz, Costil. Effect du venimde cobra sur les greffes cancereuses et sur le cancer spontane (adeno carcinoma ) de la souris, C R Acad Sci, Vol. 197: 205. 1931.

[24] M. K. Al-Sadoon, D. M. Rabah, G. Badr. Enhanced anticancer efficacy of snake venom combined with silica nanoparticles in a murine model of human multiple myeloma: molecular targets for cell cycle arrest and apoptosis induction. Cell Immunol, Vol. 284:129-38. 2013.

[25] S. Y. Hong, H. Lee, W. K. You. The snake venom disintegrinsalmosin induces apoptosis by disassembly of focal adhesions in bovine capillary endothelial cells. Biochem Biophys Res Comm, Vol. 302:502-8. 2003.

[26] C. H. Chang, C. H. Chung, C. C. Hsu. Inhibitory effects of polypeptides derived from snake venom C-type lectin, aggretin, on tumour cell-induced platelet aggregation. J Thromb Haemost, 2014. [Epub ahead of print]

[27] S. Khunshap, S. Buranapraditkum, S. Suntrarachun, S. Puthang, O. Khow, P. Chulasugandha, S. Boonchang. The effect of C. albolabris, C.rhodostoma and D. siamensis venoms on human cancer cells. Asian $\mathrm{J}$ of Biol and Life sciences, Vol. 2:50-53. 2013.

[28] D. M. Shaikh, R. Jokhia. In vitro crude cobre snake venom significantly decreases the production ofRNA and DNA in Breast cancerous tissue; Pak. J. Physiol, Vol. 2, No. 1. 2006.

[29] M. A. A. Omran. In vitro anticancer effect of scorpion Leiurus quinquestriatus and Egyption cobra venom on human breast and prostate cancer cell lines, J.Med.Sci, Vol. 3, No. 2. 66-86. 2003.

[30] A. Calmetta, A. Saenz, L. Costil. Effects du venimde cobra sur les greffes cancereuses et sur le xancerspontane (adeno carcinoma) de la souris, vC R Acad Sci, 197- 205. 1993.

[31] B. S. Basavarajappa, T. V. Gowda. Comparative characterization of two toxic phosphatases A2from Indian cobra (Najanajanaja) venom, Toxicon, Vol. 30:1227-1238. 1992.

[32] A. L. Harvey. Cardiotoxins from cobra venoms In: Reptile venoms and toxins, Tu AT. ed.,Marcel Dekker. New York. 1991.

[33] A. Gomes, P. Bhattacharjee, R. Mishra, A. K. Biswas, S. C. Das Gupta, B. Giri, A. Debnath, S. Das Gupta, T. Das, A. Gomes. Anticancer potential of animal venoms and toxins, Indian Journal of Experimental Biology, Vol. 48: 93-103. 2010 .

[34] D. S. Kim, Y. J. Jang, O. H. Jeon, D. S. Kim. Saxatilin inhibits TNF-á-induced proliferation by suppressing AP-1-dependent IL-8 expression in the ovarian cancer cell line MDAH 2774, Mol. Immunol, Vol. 44:1409-1416. 2007.

[35] M. S. Din, J. Rukhsana. Invitro crude cobra snake venom significantly decreases the production of rna\&dna in breast cancerous tissue. Pak j physiol, Vol. 2, No. 1. 2006.

[36] G. Badr, M. K. Al-Sadoon, D. M. Rabah. Snake (Walterinnesiaaegyptia) venom-loaded silica nanoparticles 
induce apoptosis and growth arrest in human prostate cancer cells. Apoptosis, Vol. 18: 300-14. 2013.

[37] S. Swenson, F. Costa, R. Minea. Intravenous liposomal delivery of the snake venom disintegrin contortrostatin limits breast cancer progression. Mol Cancer Ther, Vol. 3:499-511. 2004.

[38] Q. Xie, N. Tang, Y. Lin. Recombinant adenovirus snake venom cystatin inhibits the growth, invasion, and metastasis of B16F10 cells in vitro and in vivo. Melanoma Res, Vol. 23: 444-51. 2013
[39] P. Jakubowski, J.J. Calvete, J.A. Eble. Identification of inhibitors of alpha2betal integrin, members of C-lectin type proteins, in Echissochureki venom. Toxicol Appl Pharmacol, Vol. 269: 34-42. 2013.

[40] S. E. Lucena, K. Romo, M. Suntravat. Anti-angiogenic activities of two recombinant disintegrins derived from the Mohave and Prairie rattlesnakes. Toxicon, Vol. 78:10-7. 2014.

[41] K. Suzuki-Inoue, O. Inoue, Y. Ozaki. Novel platelet activation receptor CLEC-2: from discovery to prospects. J Thromb Haemost, Vol.. 9: 44-55. 2011. 